Oxidative stress in the lung is important in the pathogenesis of COPD. Published data indicate that glucocorticoids inhibit blood cells in their capacity to produce reactive oxygen species (ROS). We investigated the effect of Fluticasone propionate (FP) on the ROS production capabilities of pulm onary cells. Bronchoalveolar lavage (BAL) was performed in smoking COPD patien ts, before and after a six month, placebocontrolled treatment with FP. BAL cells were stimulated with phorbol myristrate acetate (PMA) alone, and together with superoxide dismutase (SOD). From kinetic plots of ferricytochrome-c conversion we calculated the maximal rate of superoxide production: $V_{\max }$. We also examined BAL cell subsets and performed correlation analyses on ROS production and relevant clinical determinants. Paired results were obtained from 6 FP- and 9 placebo-treated patients. No significant change of $V_{\mathrm{max}}$ was found in both patient groups. Also BAL cellularity was unchanged. Correlation analyses showed a significant (inverse) association of $V_{\mathrm{max}}$ with the number of cigarettes smoked per day. We concluded that a potent inhaled glucocorticoid had no effect on the ROS production capability of BAL cells from smoking COPD patients. Apparently, heavy smoking impaired the ability of alveolar macrophages to produce ROS, which was not further decreased by FP.

Key words: Reactive oxygen species, Bronchoalveolar lavage, Fluticasone propionate, Inhaled glucocorticoid, Chronic obstructive pulmonary disease, Smoking

\section{Effect of an inhaled glucocorticoid on reactive oxygen species production by bronchoalveolar lavage cells from smoking COPD patients}

\author{
Gert T. Verhoeven 1,2,CA, Annemarie J.M. Wijkhuijs ${ }^{2}$, \\ Herbert Hooijkaas ${ }^{2}$, Henk C. Hoogsteden ${ }^{1}$ and \\ Wim Sluiter ${ }^{3}$
}

${ }^{1}$ Department of Pulmonary and Intensive Care Medicine, ${ }^{2}$ Department of Immunology, ${ }^{3}$ Department of Biochemistry, Erasmus University Medical Center Rotterdam, The Netherlands

${ }^{\mathrm{CA}}$ Corresponding Author

Department of Pulmonary and Intensive Care Medicine, Erasmus University Medical Center Rotterdam, P.O. Box 2040, 3000 CA Rotterdam, The Netherlands

Tel: $+31-104634862$

Fax $+31-104634856$

Email: verhoeven@lond.azr.nl

\section{Introduction}

The airways and alveoli of patients with chronic obstructive airways disease (COPD) are invaded with numerous inflammatory cells, which have the ability to produce reactive oxygen species (ROS). ${ }^{1}$ It has been established that an increased oxidative stress is one of the major pathogenic mechanisms. ${ }^{2,3}$ Oxidative stress may occur either by an increased exposure to ROS or by a decreased capacity of the involved tissue to neutralise the constantly-emerging production of ROS. Both mechanisms seem to be involved in the development of COPD. The smoking of cigarettes is clearly related to COPD. Cigarette smoke contains several molecules, which are ROS by themselves, and it also contains molecules and particulates, which generate chemical reactions and inflammation, with subsequent ROS production. ${ }^{4}$

A major goal in the treatment of COPD is the reduction of the number and/or the activity of inflammatory cells. In asthma patients, glucocorticoids have been applied successfully with this intention. In the present study, we have investigated if a potent inhaled glucocorticoid (Fluticasone propio- nate, FP) could reduce the ROS production in COPD patients. We have selected COPD patients with bronchial hyperresponsiveness (BHR) because these patients have an exaggerated decline of their lung function. We hypothesized that inflammation and ROS production in this subgroup of COPD patients were severe, and could be influenced by an inhaled glucocorticoid. Inflammatory cells were collected by means of bronchoalveolar lavage (BAL), before and after treatment with inhaled FP or placebo. Besides cell counts, the ROS production capability was determined in vitro. Furthermore, we analyzed the association of ROS production capability with smoking behaviour, airways obstruction and BHR.

\section{Material and methods}

\section{Patients}

COPD patients were selected according to the clinical and functional criteria, which are generally accepted. ${ }^{5}$ Inclusion criteria were: age between 40 and 70 years, current smoker, $\mathrm{FEV}_{1} / \mathrm{iVC}$ ratio $\leq 70 \%$ of predicted normal values (pred), reversibility of 
$\mathrm{FEV}_{1}<10 \%$ pred after $750 \mu \mathrm{g}$ te rbutaline, non-specific BHR - defined by a PC20 histamine $\leq 8 \mathrm{mg} / \mathrm{ml}$ - and negative skin tests for standard inhaled allergens. Reference values were obtained from ECCS standards. ${ }^{6}$ The main exclusion criteria were a history of asthma and recent respiratory tract infection. Any anti-inflammatory drugs, including steroids and NSAIDs, and theophyllines were discontinued. Potential candidates for this study were informed about the negative effects of smoking, and we offered them the opportunity to participate in a smoking-cessation program. The Hospital's Medical Ethics Committee approved the study. Written informed consent was obtained from all participants.

\section{Design of the intervention study}

We performed a double blind, placebo-controlled study that lasted for six months. Patients were randomly assigned to either twice-daily $500 \mu \mathrm{g}$ FP or placebo, which were delivered via a similar diskhaler. The start of treatment was immediately after the first bronchoscopy. Bronchoscopy was repeated at the end of the study. At intervals of four weeks, the study participants had a check-up.

\section{Bronchoscopy}

The procedure was carried out according to international guidelines. ${ }^{7}$ For local anaesthesia we used lidocaine spray and aerosolised oxybuprocaine. The bronchoscope (Olympus BF 1T10) was advanced into the lateral segment of the middle lobe, in wedge position. Lavage was performed successively with $1 \times 40 \mathrm{ml}$ and $4 \times 50 \mathrm{ml}$ ste rile phosphate-buffered saline (PBS) solution (Organon Teknika, Boxtel, The Netherlands) at body temperature $\left(37^{\circ} \mathrm{C}\right)$ and $\mathrm{pH}$ 7.4. Aliquots were aspirated in two siliconized specimen traps, one for the first 'bronchoalveolar fraction' after $40 \mathrm{ml}$ PBS and the second 'alveolar fraction' for the recovery of the $4 \times 50 \mathrm{ml}$ PBS. The lavage fluid was transported to the laboratory on ice and processed immediately. The recovery of the first, bronchoalveolar fraction appeared to be low and insufficient for performing the desired experiments.

\section{Processing of BAL fluid}

After measurement of volume, the BAL fluid was filtered through sterile nylon gauzes and centrifuged at $400 \times g\left(4^{\circ} \mathrm{C}\right.$ for $\left.5 \mathrm{~min}\right)$. The cell pellet was washed in PBS supplemented with $0.5 \%$ bovine serum albumin. The total cell number in the BAL cell suspension was counted in a Coulter Counter Model ZM (Coulter Electronics, Hialeah, FL, USA) and viability was assessed by cellular exclusion of trypan blue. With FACScan flow-cytometry (Becton Dickinson, San Jose, $\mathrm{CA}$, USA) we analyzed $\mathrm{CD}^{+}$T-cells. Immunocy- tochemistry of cytospins was carried out with the APAAP (alkaline phosp-hatase anti-alkaline phosphatase) method with monoclonal antibodies CD68 (alveolar macrophages), CD15 (VIM-D5, neutrophils), and BMK-13 (eosinophils). Two independent observers counted at least 300 cells in each cytospin.

\section{Superoxide production assay}

ROS production of BAL cells was determined by the kinetic microplate assay of superoxide dismutase (SOD)-inhibitable ferricytochrome-c $(0.16 \mathrm{mM}$ horse heart cyto-chrome-c, Sigma) reduction in a 96-well microplate (Falcon 3072, Becton Bickinson, Lincoln Park, NJ). The cells, at a density of $1 \times 10^{5} / \mathrm{w}$ ell, were stimulated, in the absence and presence of SOD, with $8 \mathrm{nM}$ and $80 \mathrm{nM}$ phorbol 12-myristate 13-acetate (PMA) at $37^{\circ} \mathrm{C}$. At 18 seconds intervals the change in absorbance at $550 \mathrm{~nm}$ ( $1 \mathrm{~nm}$ bandwith) was read during $20 \mathrm{~min}$ in a Thermomax microplate reader (Molecular Devices, Sopachem, Lunteren, The Netherlands), using $540 \mathrm{~nm}(10 \mathrm{~nm}$ bandwith) as a reference wavelength. All measurements were performed in duplicate. Using the software programme SOFTmax PRO the maximum velocity $\left(V_{\max }\right)$ of ferricytochrome-c reduction was determined by calculating the first derivative of the absorbance time course in each well, and next expressed as nmol of superoxide / $\min / 10^{6}$ cells, using the difference in $V_{\max }$ in the presence and absence of SOD, the reduced minus oxidized cytochrome-c extinction coefficient of $21.1 \mathrm{mM}^{-1} \mathrm{~cm}^{-1}$, and the empirically determined light path length. Since we found the $V_{\max }$ upon stimulation with $80 \mathrm{nM}$ PMA did not increase further as compared to $8 \mathrm{nM}$ PMA, apparently the cells were already maximally stimulated at the lowest PMA concentration. Therefore, we present these data as the mean and do not refer to the PMA concentration.

\section{Statistical analysis}

Pre- and post-intervention data were tested for significant difference with the paired $t$-test. Differences between patient groups were tested with either the (unpaired) Student $t$-test or the Mann-Whitney test, depending upon distribution of data. Correlation studies were performed with the Spearman rank test. Statistical significance was considered at $p<0.05$.

\section{Results}

From the initial 23 participants in the intervention study, paired results were obtained from 6 FP patients and from 9 patients with placebo. The reasons for missing paired data were insufficient recovery of either BAL fluid or BAL cells. The patient characteristics $(n=15)$, listed in Table 1 , show that on average 
Table 1. Patient characteristics (mean \pm SD)

\begin{tabular}{lcc}
\hline & Fluticasone propionate & Placebo \\
\hline$N$ & 6 & 9 \\
Age & $56 \pm 7$ & $57 \pm 9$ \\
Cigarettes/day & $17 \pm 8$ & $15 \pm 5$ \\
Packyears $_{\text {FEV }} \%$ pred & $25 \pm 12$ & $27 \pm 10$ \\
FEV $_{1}$ reversibility & $72 \pm 12$ & $68 \pm 13$ \\
PC $_{20}$ histamine & $4.6 \pm 2.4$ & $5.3 \pm 2.4$ \\
& $3.3 \pm 3.2$ & $0.8 \pm 0.6$ \\
\hline
\end{tabular}

these patients had moderately severe obstructive airways disease and severe BHR. Compliance with study medication was high: the percentage of returned used blisters was 92.5 in the FP and 92.7 in the placebo group.

Differences in baseline characteristics between the FP and the placebo group were not statistically significant. In the placebo group, mean $\mathrm{FEV}_{1}$ declined from $68.5 \%$ pred at the start of the trial to $52.0 \%$ pred after 6 months. However, lung function remained unchanged in the FP group (mean $\mathrm{FEV}_{1}: 72.4$ and 69.1\%pred, respectively). This treatment effect was statistically significant, and considered as a beneficial effect of FP treatment.

\section{Immunocytology}

Mean total cell number of the BAL at the start of the trial was $53.0 \times 10^{6}$ for FP treated patients and $45.3 \times 10^{6}$ in the placebo group (Table 2). Small changes were noticed in the BAL cell numbers at the end of the trial, which were not significant (Table 2). The percentages of fluid recovery, cell viability and cell types were not statistically different between both patient groups, before intervention, and did not change significantly after 6 months of intervention (Table 2). The low number of eosinophils indicates that COPD was stable in nature.

\section{ROS production capability}

Figure 1 shows $V_{\max }$ of the patients from the FP and the placebo group, before and after intervention.

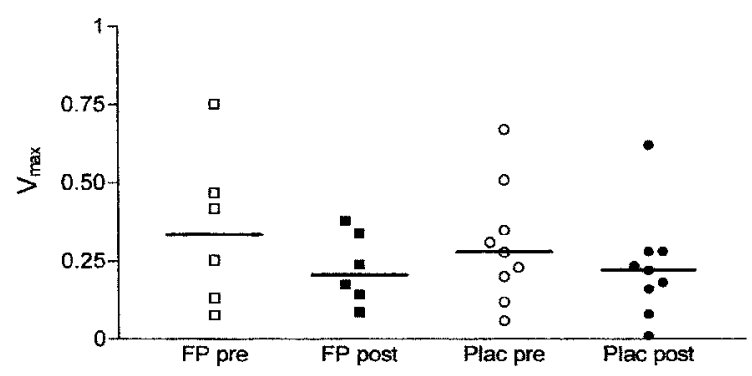

FIG. 1. Results of the superoxide production assay. $V_{\text {max }}$ : maximum velocity of reactive oxygen species production, $\mathrm{nmol} / \mathrm{min} / 10^{6}$ cells; FP: Fluticasone propionate; Plac: placebo; pre: pre-intervention; post: post-intervention.

$V_{\max }$ ranged from 0.076 to 0.753 (mean 0.35 ) nmol superoxide $/ \mathrm{min} / 10^{6}$ cells in the FP treated patients, and from 0.06 to 0.67 (mean 0.303 ) in the placebo group. Statistical analysis showed that there were no significant changes after FP or placebo.

\section{Association of $V_{\max }$ with airways obstruction, BHR and smoking status}

There were no significant correlations between pretreatment $V_{\max }$ on the one hand, and $\mathrm{FEV}_{1}$ and $\mathrm{PC}_{20}$ on the other. However, the actual number of cigarettes smoked per day correlated significantly with pre-treatment $V_{\text {max }}$ (Fig. 2, $R=-0.67, p=0.007$, Spearman rank test). There was no significant correlation of $V_{\max }$ and packyears of smoking.

\section{Discussion}

In this double blind, placebo controlled trial, we observed no significant effect of a potent inhaled glucocorticoid on the ROS production capability $\left(V_{\max }\right)$ of BAL cells derived from a subgroup of COPD patients, namely those with bronchial hyperresponsiveness. At first glance, this result appears to be

Table 2. Characteristics of bronchoalveolar lavage (mean \pm SD)

\begin{tabular}{|c|c|c|c|c|}
\hline & \multicolumn{2}{|c|}{ Fluticasone propionate } & \multicolumn{2}{|c|}{ Placebo } \\
\hline & Start & 6 months & Start & 6 months \\
\hline Fluid recovery, \% & $60 \pm 13$ & $62 \pm 11$ & $54 \pm 16$ & $51 \pm 19$ \\
\hline Cell number, $\times 10^{6}$ & $53 \pm 13.5$ & $59 \pm 31$ & $45.3 \pm 22.7$ & $36.4 \pm 18$ \\
\hline Cell viability, \% & $62 \pm 12$ & $66 \pm 12$ & $70 \pm 13$ & $67 \pm 12$ \\
\hline $\mathrm{CD}^{+} 8^{+}$macrophages, \% & $95 \pm 3$ & $95 \pm 4$ & $95 \pm 4$ & $91 \pm 5$ \\
\hline CD15 ${ }^{+}$granulocytes, \% & $2.4 \pm 2.8$ & $1.9 \pm 1.2$ & $3.1 \pm 2.8$ & $4.2 \pm 7.5$ \\
\hline BMK $13^{+}$eosinophils, \% & $0.4 \pm 0.3$ & $0.8 \pm 0.5$ & $0.4 \pm 0.3$ & $0.8 \pm 1.0$ \\
\hline $\mathrm{CD}^{+}$T-cells, $\%$ & $2.0 \pm 2.9$ & $0.7 \pm 0.9$ & $3.0 \pm 2.9$ & $3.0 \pm 6.5$ \\
\hline
\end{tabular}




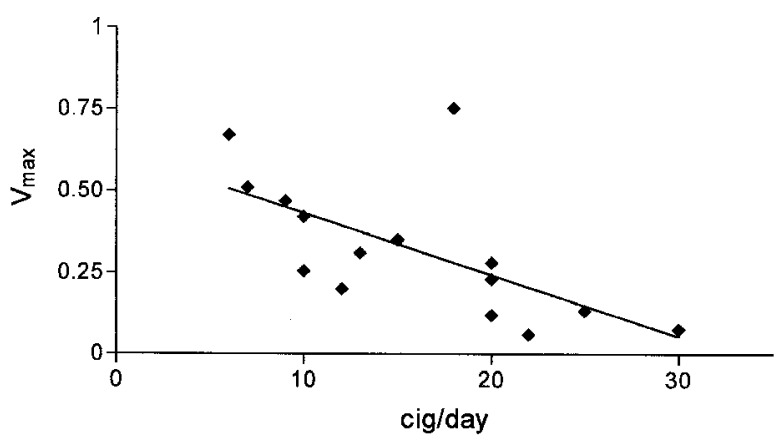

FIG. 2. Correlation of reactive oxygen species production and smoking. $R=-0.67, p<0.01$ (Spearman rank test).

$V_{\text {max }}$ : maximum velocity of reactive oxygen species production, $\mathrm{nmol} / \mathrm{min} / 10^{6}$ cells; Cig/day: number of cigarettes smoked per day.

related to the absence of a decrease in the number of inflammatory cells in the BAL. Our correlation studies indicated that actual smoking status is an important confounding factor. With increasing number of cigarettes smoked per day, $V_{\max }$ decreases.

As the re has not been published a similar study in COPD patients before, we compared our results with studies concerning the effects of glucocorticoids on ROS production capacity of blood-derived cells, and with studies concerning the effect of smoking.

In one study, the superoxide production by PMAstimulated blood granulocytes, taken from 18 miscellaneous patients on oral glucocorticoid treatment, was decreased as compared to healthy controls. ${ }^{8}$ Superoxide production by blood granulocytes of patients with emphysema was decreased after in vivo prednisolone treatment. ${ }^{9}$ However, dexamethasone, both in vitro and in vivo, did not alter the spontaneous superoxide release of blood granulocytes from healthy volunteers. ${ }^{10}$

The reported studies concerning the effect of smoking on ROS production capability are not consistent. Alveolar macrophages (AM) from healthy smokers produced more superoxide than AM from nonsmoking control subjects. ${ }^{1-13}$ Exposure to tobacco smoke in vitro increased the oxidative metabolism of $\mathrm{AM}^{14}$ while it reduced superoxide generation by blood granulocytes. ${ }^{15}$ Hoidal et al. used almost the same lavage method as in our study, and compared young asymptomatic smokers with nonsmokers. ${ }^{11}$ They reported that BAL cells from smokers, stimulated with PMA, produced on average $1.93 \mathrm{nmol} \mathrm{ROS} / \mathrm{min} / 10^{6}$ cells, while $\mathrm{BAL}$ cells from nonsmokers produced $0.945 \mathrm{nmol}$ ROS/ $\mathrm{min} / 10^{6}$ cells. We found an average (pre-intervention) ROS production of $0.322 \mathrm{nmol} / \mathrm{min} / 10^{6}$ cells $(n=15)$. The low ROS production capability in our study could either be due to patient selection (COPD), the presence of BHR, different BAL cell counts or to smoking. ROS production by BAL cells from smokers without COPD was not different from smokers with COPD. ${ }^{16}$ Therefore, the diagnosis of COPD seems to be unimportant. Furthermore, since the level of PC20 was not significantly correlated with $V_{\max }$, and the cell profile in BAL resembles the reported findings in 'average' COPD patients and smokers, the first three options are not likely. However, our correlation analyses indicate that cigarette smoking influences ROS production capability. A possible explanation could be that viable macrophages lose their ability to release superoxide after repeated stimulation. ${ }^{17}$ This was attributed to ligand-induced desensitisation of specific receptors. This phenomenon might also have occurred in our heavy smoking COPD patients.

In conclusion, the BAL cells from smoking COPD patients with BHR, consisting mainly of alveolar macrophages, have a low ROS production capability. This was not further decreased by in vivo ex posure to a potent inhaled glucocorticoid. The low ROS production capability might be one of the causative mechanisms of the increased susceptibility to respiratory tract infections and the increased frequency of bacterial colonisation of the airways in these COPD patients.

ACKNOWLEDGEMENTS: The authors would like to thank Dr RJ. van Klaveren for critically reading the manuscript, and GlaxoWellcome, The Netherlands (FLIL44/FMS40060), for their financial support

\section{References}

1. Jeffery PK. Comparative morphology of the airways in asthma and chronic ob-structive pulmonary disease. Am J Respir Crit Care Med 1994: 150:S6-S13.

2. Cantin AM, Crystal RG. Oxidants, antioxidants and the pathogenesis of emphysema. Eur J Respir Dis 1985:66:7-17.

3. Re pine JE, Bast A, Lankhorst I, and the oxidative stress study group. State of the art: oxidative stress in chronic obstructive pulmonary disease. $\mathrm{Am}$ J Respir Crit Care Med 1997:156:341-57.

4. Pryor WA, Stone K. Oxidants in cigarette smoke: radicals, hydrogen peroxides, peroxynitrate, and peroxynitrite. Ann $N$ Y Acad Sci 1993:686:12-28

5. ATS Statement. Standards for the diagnosis and care of patients with chronic obstructive pulmonary disease. Am J Respir Crit Care Med 1995: 152:S77-S120.

6. Quanjer PH. Lung volumes and forced expiratory flows. Re port Working Party Standardization of lung function tests, European Community for Steel and Coal. Eur Respir J 1993:6 (Suppl 16):5-40.

7. Workshop summary and guidelines: investigative use of bronchoscopy, lavage and bronchial biopsies in asthma and other airways diseases. $A m$ Rev Respir Dis 1991:135:250-63.

8. Fukushima K, Ando M, Ito K, et al. Stimulus- and cumulative dosedependent inhibition of O2-production by polymorphonuclear leukocytes of patients receiving corticosteroids. J Clin Lab Immunol 1990:33:117-23.

9. Renkema TE, Postma DS, Noordhoek JA, et al. Influence of in vivo predn isolone on increased in vitro $\mathrm{O} 2$-generation by neutrophils in emphysema. Eur Respir J 1993:6:90-5.

10. Lomas DA, Ip M, Chamba A, Stockley RA. The effect of in vitro and in vivo dexamethasone on human neutrophil function. Agents Actions 1991:33:279-85.

11. Hoidal JR, Fox RB, LeMarbe PA, et al. Altered oxidative metabolic response in vitro of alveolar macrophages from asymp-tomatic cigarette smokers. Am Rev Respir Dis 1981:123:85-9. 
12. Nakashima H, Ando M, Sugimoto M, et al. Receptor-mediated O2-release by alveolar macrophages and peripheral blood monocytes from smokers and nonsmokers. Am Rev Respir Dis 1987:136:310-5.

13. Schaberg T, Haller H, Rau M, et al. Superoxide anion release induced by platelet-activating factor is increased in human alveolar macrophages from smokers. Eur Respir J 1992:5:387-93.

14. Drath DB, Karnovsky ML, Huber GL. The effects of experimental exposure to tobacco smoke on the oxidative metabolism of alveolar macrophages. J Reticuloendo thelial So ciety 1970:25:597-604.

15. McLeod RG, Mack DG, McLeod EG, et al. Alveolar macrophage function and inflammatory stimuli in smokers with and without obstructive lung disease. Am Rev Respir Dis 1985:131:377-84.
16. Tsuchiya M, Thompson DF, Suzuki YJ, et al. Superoxide formed from cigarette smoke impairs polymorphonuclear leukocyte active oxygen generation activity. Arch Biochem Biophys 1992:299:30-7.

17. Berton G, Gordon S. Desensitization of macrophages to stimuli which induce secretion of superoxide anion. Down-regulation of receptors for phorbol myristate acetate. Eur J Imm unol 1983:13:620-7.

\section{Accepted 8 May 2000}




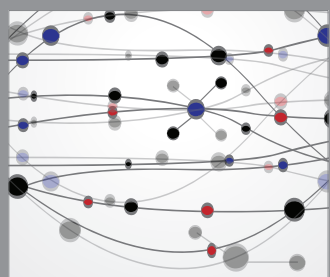

The Scientific World Journal
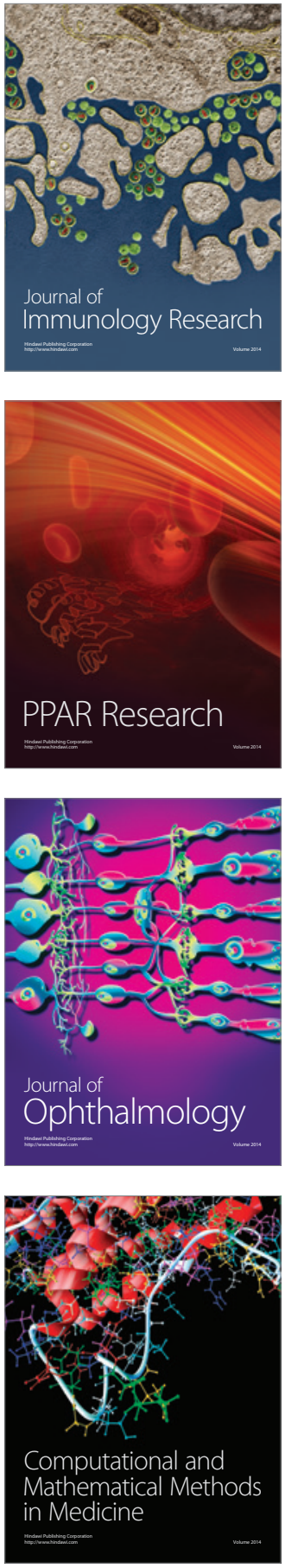

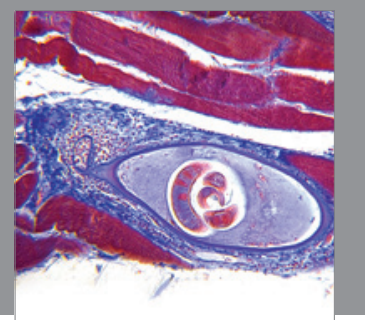

Gastroenterology

Research and Practice
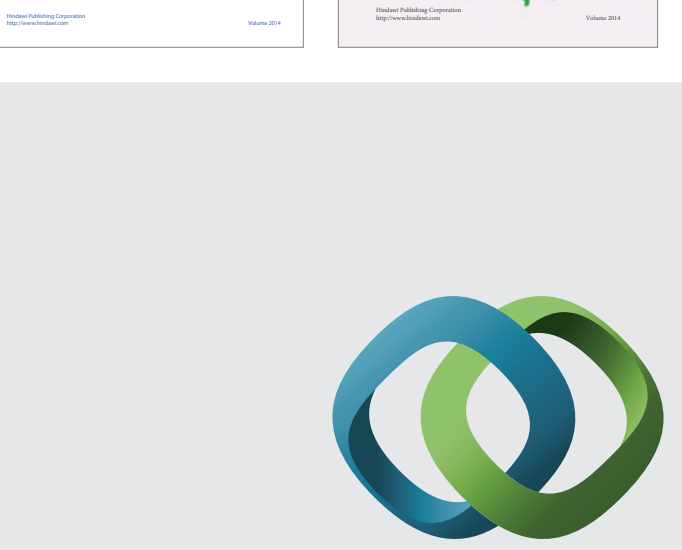

\section{Hindawi}

Submit your manuscripts at

http://www.hindawi.com
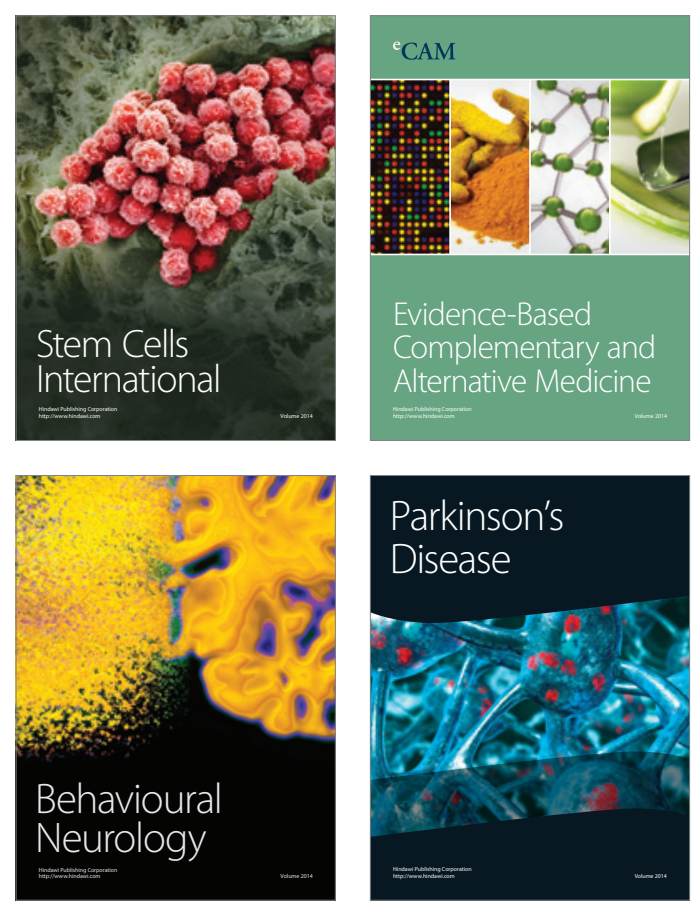

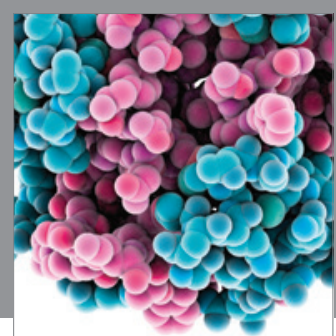

Journal of
Diabetes Research

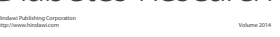

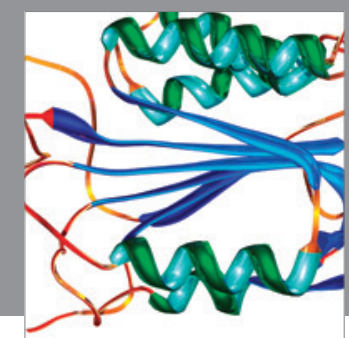

Disease Markers
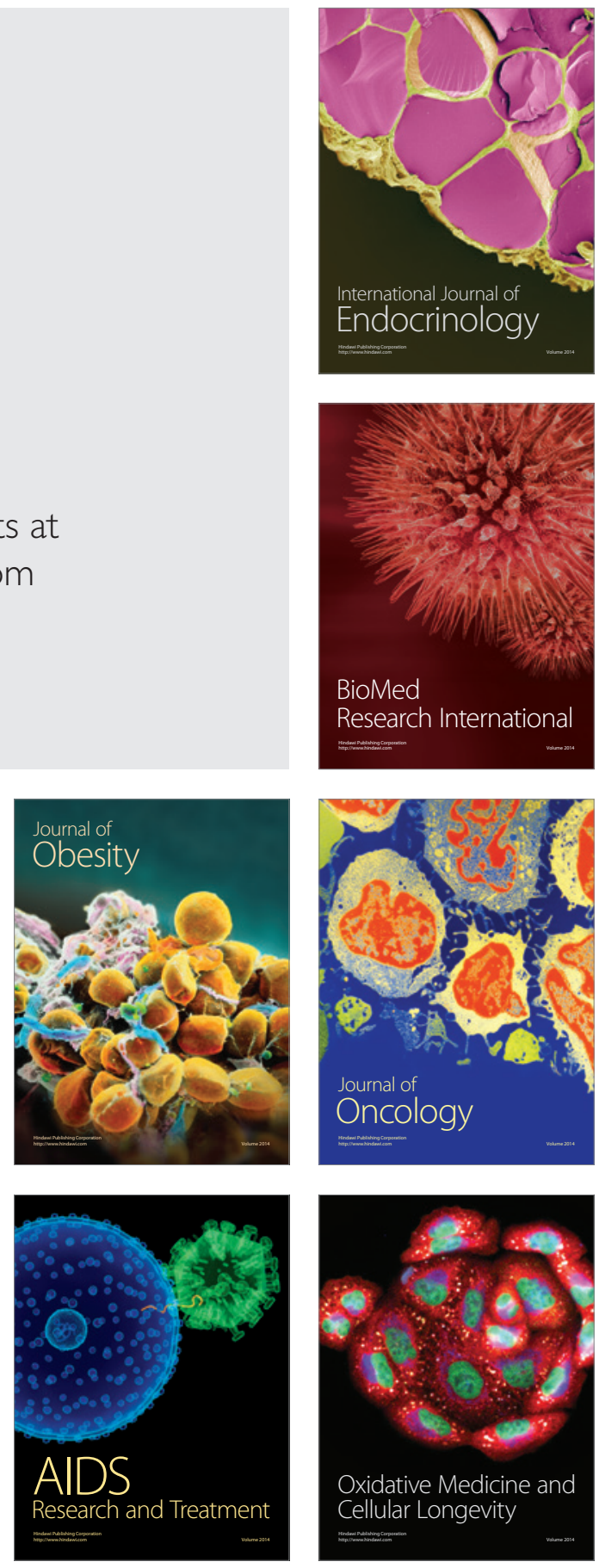